\title{
Analysis on the Change of India's Billionaires and Its Reasons
}

\author{
Shujun Jin \\ Northeast Yucai School, Liaoning, 110000, China
}

\begin{abstract}
Today the cultural communication between different countries and regions is intensified. Indian has won the attention of many people as a rising star in the market. In this article, an issue of intense debate, India's billionaires, is the main theme. The knowledge source of this article involves the contents of authoritative books, treatises of other intellectuals, and the data on the Internet. According to the analysis, the conclusion can be drawn that India's rich hold much fortune, which may be caused by its economic reform and crony capitalism. This article also hypotheses the future trend of the outlook: the number of Indian billionaires may still continue to increase. Nevertheless, under the help of Indian government and the improving institution, the increasing speed will be much slower and the trading behaviour of the upper class, which tends to be connected with the word corruption, may also be more legitimate.
\end{abstract}

\section{INTRODUCTION}

With the world gradually shrinking into a small global village, the issue of sweeping globalization has triggered heated debate. Trade between countries is increasing and the bonds become closer. With the continuous flourishing of the global economy, it is difficult for a country to be immune to global affairs. As the law of large numbers says, the richer a country is, the harder it is to grow national wealth at a rapid pace, and this economic gravity has already pulled China, Russia, Brazil, and other big emerging markets back to earth [1]. Therefore, there is a decreasing number of potential breakout nations. India's potential as a breakout nation has sparked off an intense controversy.

In addition, India is famous for its wealth gap. Poor people are very poor. They are even unemployed and languish in the farm regions, while rich people are very affluent. According to the 2019 Forbes list, there are 119 Indian billionaires, 8 of whom have more than 10 billion dollars. They control much of India's wealth, much of which has been accumulated through corruption, and this provokes resentment among the poor and negative worldwide attention. Why do India's rich have so much wealth, while China's wealth is much less concentrated despite having more billionaires? And what leads to the rise of Indian billionaires? In this article, the change of India's billionaires over time and the driving force behind it will be analyzed. Through this analysis, a general overview of the India's current situation can be obtained and systematic prospects of the developing direction of Indian billionaires in the future can be drawn.

\section{DEVELOPMENT AND CAUSES}

\subsection{General overview of Indian billionaires}

It is worth mentioning of the changes on Forbes India's rich list from 2018 to 2019. The following arguments are a summary of the data on the Forbes list. The first position remains Mukesh Ambani, whose booming telecommunications company Jio has added $\$ 4.1$ billion to his net worth. Azim Premji, a business giant who has a reputation of "Bill Gates of India", dropped from the second place in 2018 to 17 th place in 2019 , with his net worth down by nearly a third to $\$ 13.8$ billion. Steel king Lakshmi Mittal lost $\$ 7.8$ billion in wealth due to falling steel prices and weak demand. Acharya Balkrishna's wealth has fallen by more than two-thirds and Vivek Chaand Sehgal has lost more than half its value as global demand for cars has slowed. Given the above situations, where the loss outweighed the gain, 2019 is depressed year for the Indian rich.

However, in the early years, India had relatively more rich people among the emerging economies, which can be seen in fig. 1. 


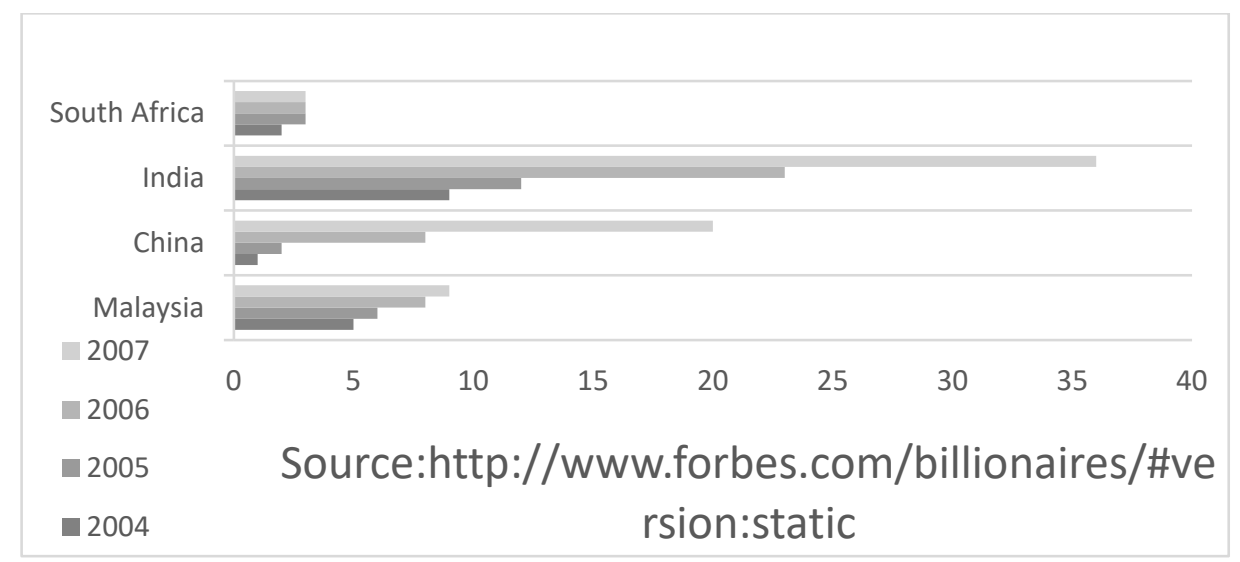

Figure 1 The number of billionaires from 2004 to 2007

New faces can often be seen on China's billionaires list, and there are many richest billionaire newcomers on the 2019 Forbes list, whereas India's top few seem to be considerably stable. "The top ten Indian tycoons on the 2010 billionaire list controlled wealth equal to 12 percent of GDP --- compared to only 1 percent in China. Nine of India's top ten were holdovers from 2006 compared to zero in China."[2] Furthermore, when looking at the Forbes list of India's richest people over the past decade, Mukesh Ambani can be found to be consistently topped the list. This relative stability does not bode well, since it manifests that tycoons always have a way of creating and maintaining their fortunes, and this way is often through inextricable links to officials.

TABLE I. AN OVERVIEW OF INDIAN GDP AND THE WEALTH POSSESSED BY ITS 100 RECHEST

\begin{tabular}{|c|c|c|c|}
\hline Year & $\begin{array}{c}\text { The wealth of the } 100 \text { richest } \\
\text { Indians } \\
\text { (in billion dollars) } \\
\text { Source: Forbes.com }\end{array}$ & $\begin{array}{c}\text { Indian GDP } \\
\text { (in billion dollars) } \\
\text { Source: worldbank }\end{array}$ & $\begin{array}{c}\text { Proportion } \\
\text { (the 100 richest/all } \\
\text { citizens, \%) }\end{array}$ \\
\hline 2009 & 275.7 & 1341.9 & 20.5 \\
\hline 2010 & 300.5 & 1675.6 & 17.9 \\
\hline 2011 & 241.5 & 1823 & 13.2 \\
\hline 2012 & 250.7 & 1827.6 & 13.7 \\
\hline 2013 & 258.7 & 1856.7 & 13.9 \\
\hline 2014 & 345.7 & 2039.1 & 17.0 \\
\hline 2015 & 345.3 & 2103.6 & 16.4 \\
\hline 2016 & 381.3 & 2290.4 & 16.6 \\
\hline 2017 & 479 & 2652.6 & 18.1 \\
\hline 2018 & 492 & 2726.3 & 18.0 \\
\hline
\end{tabular}

As can be seen in tab. 1, India's GDP has always been growing. The wealth held by the rich as a share of the country's wealth was relatively high in the early years. In contrary, it was well controlled in 2011. This situation remained stable until 2013, when the proportion began to rise again. Calculators give a regression line of Proportion $=0.75119$ (Years-2011) +13.2333 with $\mathrm{r}^{2}=$ 0.867538 . With this equation, the proportion can be predicted to be around $20 \%$ in 2020 .

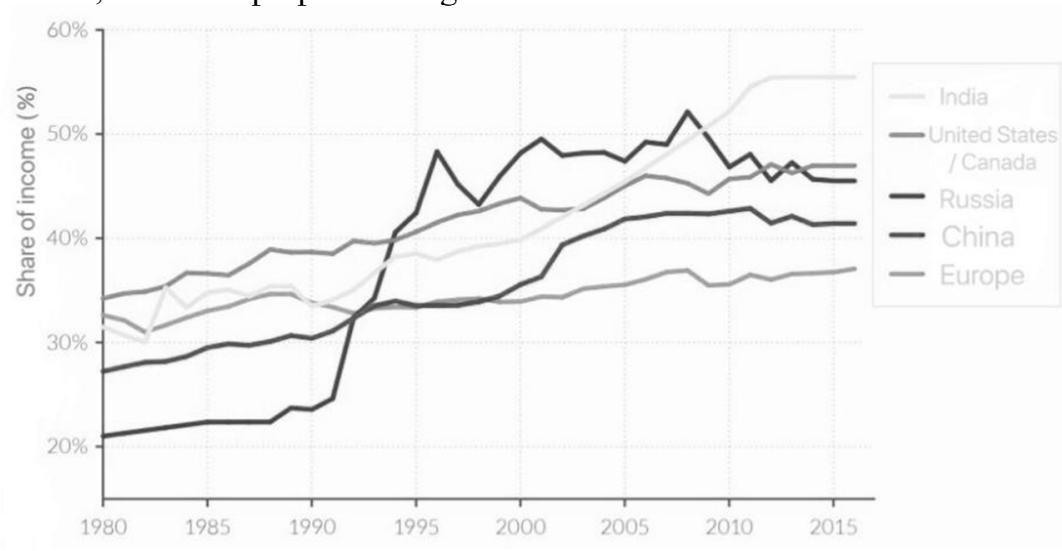

Figure 2. The share of income earned by the top $10 \%$ of adults in each region of the world [8]. 
It is reasonable to conclude from fig. 2 that the income inequality is widening in most countries, but at different rates. Among these regions, North America had the most severe income gap problem initially, until around the year 1994, when Russia's curve overtook North America's, and then around 2008, India outperformed Russia and the rest, occupying the first place. During this time interval in the graph, Russia's curve has witnessed a steep increase from 1991 to 1996, and then remained more stable, with a little downward trend in recent years; however, the share of income earned by Indian top $10 \%$ is growing at a relatively fast pace. Because of Indian policies and other factors, the income disparity has continued to increase, and the tycoons have accumulated more and more wealth, but the living conditions of the people at the bottom have hardly changed. As a result, India's wealth has become much concentrated.

With this increasing income inequality and seemingly not so healthy billionaire system, it is India that hooks many economists' curiosity. The reasons behind this situation are also compelling.

\subsection{The reasons behind the rise and the change of Indian billionaires}

2.2.1. Economic reforms in 1991: Before the 1991 economic reform, India did not liberalize its economy and was closed to the outside world. Given that the world economic situation had changed, India had to implement an economic reform to keep up with the times.

Since the 1990s, the Indian economy has stepped out of the low-medium growth curve and started to cross the medium-high growth platform, with the average annual growth rate rising from about $5.5 \%$ in the 1980 s to $61 \%$ in the 1990s [3]. The reform also attracted a lot of foreign investment, which is shown in the following figure, so India's economy has gradually flourished and Indians have become richer and richer.

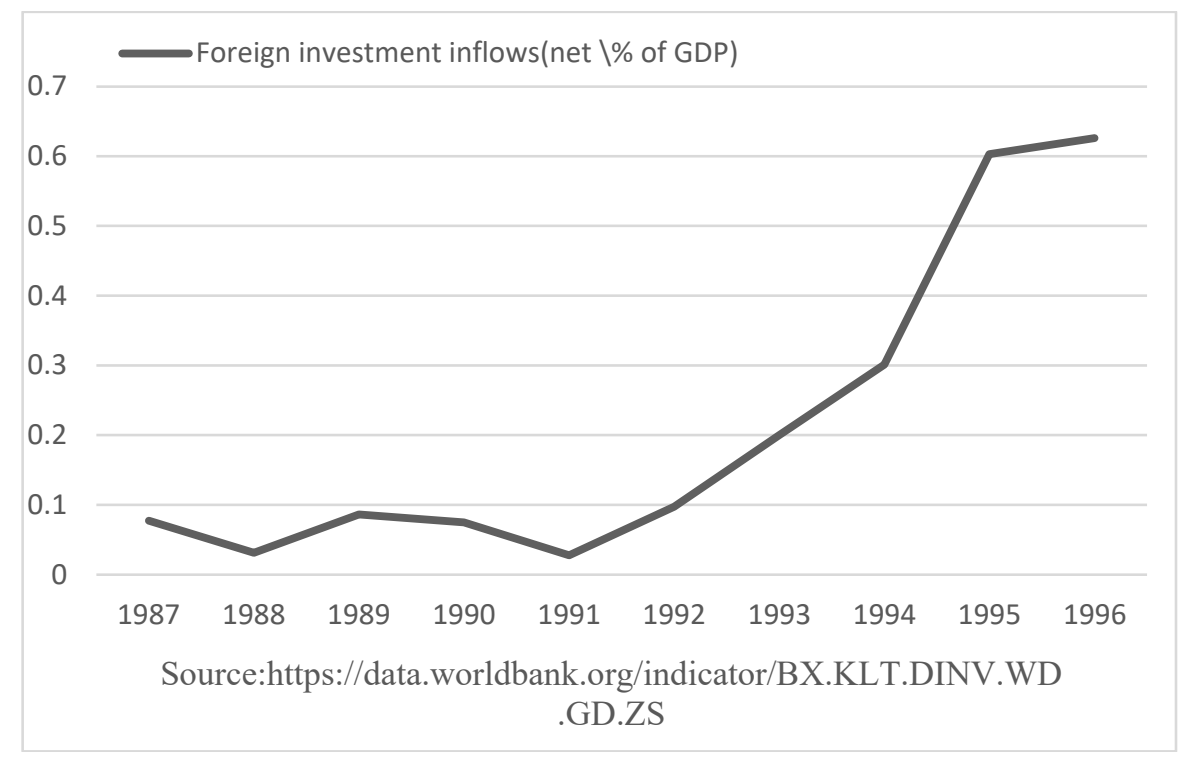

Figure 3. Foreign investment inflows to India from 1987 to 1996.

2.2.2 Crony capitalism: In 1997, the currency crisis and the banking crisis led to the financial crisis. Foreign investors, worried about the solvency of developing countries, pulled money out of Indonesia, Thailand, South Korea, Malaysia and the Philippines, resulting in huge foreign debts for the five countries. The financial crisis spread to the rest of Asia because of the trades between countries. Since then, the term "crony capitalism" has become popular.

The phenomenon of nepotism generally refers to the political and economic benefits obtained by blood relatives, in-laws and close friends, as well as the special protection, promotion and reward given by political leaders to loyalists and followers. Crony is a group of members who interact closely, support each other, and act dishonestly for each other' s benefit [4]. Asia's crony capitalism often involves powerful people using their wealth and power to protect the weak, who then loyally work for them. India also suffers from this. The global crony capitalism index shows that Hong Kong is the worst place for crony capitalism, while India also ranks high, the 10th [5]. It is crony capitalism that renders the fortune concentrated and stabilizes the position of the rich who own crony industries. For example, India's richest man Ambani has a huge group, Reliance. It controls 3.5\% of India's GDP, accounts for $10 \%$ of the country's tax revenues, and accounts for nearly $6 \%$ of the market capitalization of India's listed companies [6]. This significant status also suggests some relationship, which may be a reason for his first position on the list for many years. Furthermore, the government's macro-control tools, such as subsidies, allow corruption to flourish, strengthening the relationship between the billionaires and politicians and giving them more opportunities to create ill-gotten gains. However, in the emerging world, the share of billionaires' wealth derived from nepotism is falling, from a peak of $76 \%$ in 2008 to $58 \%$ in 2014 [7]. Therefore, the situation will be more and more optimistic. 


\section{THE IMPLICATION OF INDIA'S BILLIONAIRE PROBLEM ON CHINA}

India and China are both developing countries with large population bases. In the early stage of development, they both gave the priority to the development of heavy industry. Based on so many similarities, they are often compared by people.

As the article stated before, the number of Indian billionaires is out of proportion to the size of its economy, and billionaires generate too much money, which suggests an off-balance in Indian economy. Furthermore, much of India's wealth is produced through the corruption, the cozy relationship with politicians, not by productive careers. From fig. 4, which can be a reflection of the productivity in a country, India's productivity is far fewer than China's. Hence, though with its demographic dividend, India has little increase in its total factory productivity. Therefore, it should increase more productive careers and raise the wage level to solve the employment problem, which is also a revelation to China.

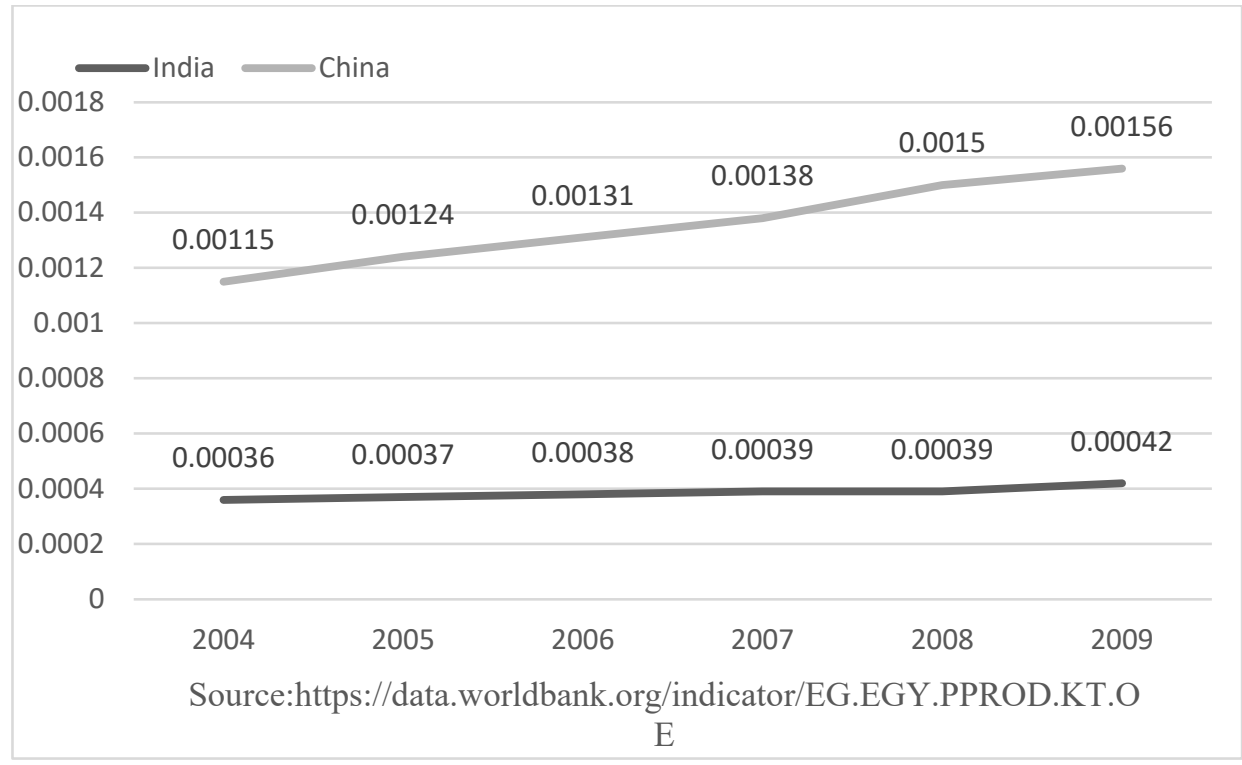

Figure 4. Energy production per person in India and China.

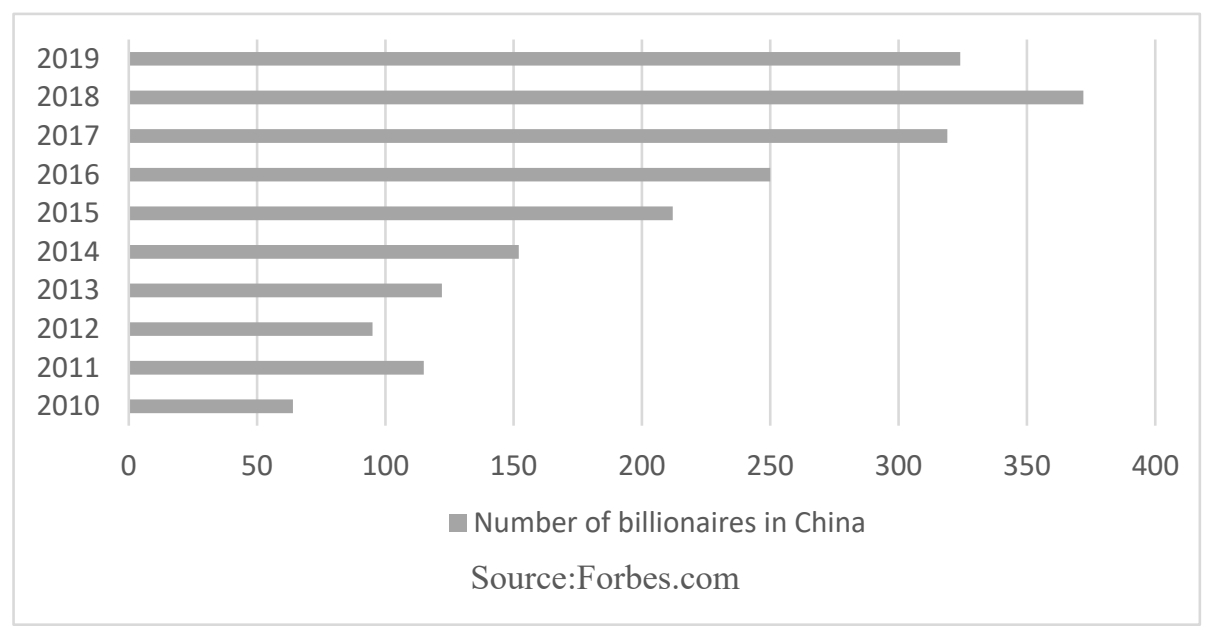

Figure 5. Billionaires in China annually from 2010 to 2019.

From fig. 5, the number of billionaires in China as a whole is growing at a relatively fast pace, although it fell in 2012 and 2019. Despite the fact that China is now restricting the wealth of the rich and giving them more attention, what needs to be done to establish a healthy social system in an effort to prevent the huge gap between the rich and the poor and serious corruption like India cannot be emphasized any more.

\section{CONCLUSION}

Through the analysis of the data, the conclusion can be drawn that India has a number of billionaires, which is unmatched with its economy size, suggesting an off-balance. Although the widening gap between the rich and the poor is a necessary process for developing countries to flourish, there is such a great disparity in India, which is of great significance. The wealth gap is still a pressing issue. Moreover, what kind of measures 
the government should take has sparked off a spirited controversy.

\section{ACKNOWLEDGEMENT}

First and foremost, I would like to show my deepest gratitude to my teachers and professors in my university, who have provided me with valuable guidance in every stage of the writing of this thesis. Further, I would like to thank all my friends and roommates for their encouragement and support. Without all their enlightening instruction and impressive kindness, I could not have completed my thesis.

\section{REFERENCES}

1. R. Sharma, Breakout Nations: In pursuit of the next economic miracles.

2. R. Sharma. The Rise and Fall of Nations: Forces of Change in the Post-crisis World.

3. J. Ma, The rise of India. Modern international relations, 2006, vol. 6 .

4. L. Zhuang, Asian Pain---Dissecting "Crony Capitalism”. MagReaderHD-NFC, 2001, vol. 06, pp. 74-77.

5. G. K. Zhang, The Economist publicize the crony capitalism ranking: Hong Kong tops, China behind US. Shanghai's economy, 2014, vol. 5, pp. 25-25.

6. R. Li, The myth of the richest man in Ambani. Business story, 2011, vol. 2, pp. 74.

7. Y. Zhang, The second era of crony capitalism]. Operator, 2014, vol. 10, pp. 40-41.

8. Data retrieved on March 7. 2020, from: m.book118.com. 